\title{
PERSPEKTIF ETIKA BISNIS MAHASISWA TERHADAP PENGGUNAAN SOFTWARE ASLI DAN BAJAKAN DI KOTAMADYA PONTIANAK
}

\author{
Hijrah Wahyudi \\ yudihwy.hw@gmail.com \\ STIE Indonesia Pontianak \\ Mardiyati \\ myathie_yd@yahoo.com \\ STIE Pontianak
}

\begin{abstract}
The purpose of this research is to know the college student's perspective of business ethic about genuine software fake software; to socialise and disseminate some freewares to the college students. This analysis is done by using descriptive analysis in order to answer the research. This research is done to 100 college students ( 50 persons from STIE Indonesia Pontianak, and 50 persons from STIE Pontianak). Result of the research concludes that happened gap, in which the perspective of business ethic is above the piracy of the software. .
\end{abstract}

Key word: Business Ethic, College Students, Genuine Software and Fake Software.

\section{PENDAHULUAN}

Di era ekonomi digital ini, ditandai dengan kemajuan perangkat teknologi informasi sudah tidak dapat dibendung lagi, setiap saat ada saja produsen yang mengeluarkan produk terbaru yang tentunya dengan membawa teknologi yang baru juga. Berbeda dengan di era ekonomi lama (konvensional) dimana produk teknologi informasi dijual dengan kuantitas merek yang terbatas tetapi harganya mahal, sekarang (era ekonomi digital) produk tersebut dijual dengan kuantitas merek yang banyak dan harga yang terjangkau.

Juniarto dalam Majalah Chip (2010) menyatakan bahwa sudah terjadi ketergantungan digital, yaitu ketika teknologi digital yang awalnya identik dengan komputer, telah merambah ke berbagai bidang kehidupan manusia. Banyak media yang awalnya analog, seperti musik, foto, video, dan dokumen-dokumen yang tadinya berbentuk hardcopy telah mengalami transformasi ke dalam bentuk digital. Teknologi digital ini mirip dengan pisau bermata dua, di satu sisi pihak mempermudah kegiatan manusia sehari-harinya, di sisi lain juga makin mempermudah penyebaran berkas yang isinya bisa menghancurkan kehidupan orang lain.
Sejalan dengan pendapat Juniarto tersebut, tidaklah mengherankan apabila di era ekonomi digital sekarang ini, para mahasiswa banyak menggunakan produk teknologi informasi sebagai alat bantu dalam proses kegiatan belajar dan mengajar. Misalnya, untuk mencari materi kuliah para mahasiswa sudah terbiasa menggunakan bantuan mesin pencari (search engine) di internet; untuk menyimpan materi kuliah para mahasiswa sudah tidak asing lagi dengan perangkat penyimpanan berkas seperti flashdisc, SD card, memory card, hardisk-external, dan lain sebagainya.

Fenomena tersebut muncul dikarenakan perubahan perilaku kegiatan belajar-mengajar dimana para pengajar sering memberikan materi kuliah berupa files berbentuk softcopy. Hal ini tentu saja positif bagi perkembangan kemampuan menguasai teknologi baik untuk para mahasiswa maupun para pengajar. Namun, perubahan perilaku tersebut tidak diiringi dengan perilaku/ tindakan etis dalam hal penggunaan perangkat lunak (software) teknologi informasi. Tidak sedikit dari kita yang menggunakan perangkat lunak bajakan. Contohnya, ketika pengajar memberikan materi kuliah dalam bentuk presentasi kebanyakan menggunakan perangkat lunak Microsoft Office PowerPoint, 
Microsoft Office Excel, Microsoft Office Word, dan lain sebagainya.

McLeod (2001) menyatakan bahwa sekarang terdapat perhatian yang lebih besar pada etika dalam penggunaan perangkat teknologi informasi dibanding sebelumnya. Masyarakat secara umum memberikan perhatian utama karena kesadaran bahwa perangkat teknologi informasi dapat mengganggu hak privasi individu. Dalam dunia bisnis, salah satu alasan utama terhadap perhatian tersebut adalah pembajakan perangkat lunak yang menggerogoti pendapatan penjual perangkat lunak hingga miliaran dollar setahun.

Perilaku menggunakan perangkat lunak tanpa izin (bajakan) dapat dikategorikan sebagai perilaku/tindakan tidak beretika. Namun, karena adanya perbedaan budaya di masyarakat dunia menyebabkan perbedaan terhadap masalah ini.

McLeod (2001) menyatakan bahwa tindakan seperti moral, etika dapat sangat berbeda dari satu masyarakat ke masyarakat lain. Perbedaan ini dapat dilihat di bidang komputer dalam bentuk perangkat lunak bajakan (perangkat lunak yang digandakan secara ilegal lalu digunakan atau dijual. Pada tahun 1944 diperkirakan 35\% perangkat lunak yang digunakan di Amerika Serikat telah dibajak, dan angka ini melonjak menjadi 92\% di Jepang dan 99\% di Thailand. Angka-angka tersebut menunjukkan bahwa para pemakai di Jepang dan Thailand kurang etis dibandingkan di Amerika Serikat. Namun tidak demikian. Beberapa kebudayaan, terutama di negara-negara Timur, menganjurkan sikap berbagi. Suatu pepatah Cina mengatakan, "Orang yang berbagi patut dihargai; orang yang tidak berbagi patut dicerca".

Untuk mengidentifikasi masalah yang akan dipecahkan dalam penelitian ini, maka ditampilkan beberapa fenomena perilaku tidak etis dalam penggunaan perangkat teknologi informasi yang sering terjadi sebagai berikut:

1. Masih ada pihak-pihak yang menggunakan perangkat lunak bajakan untuk pengolah kata, biasanya menggunakan MS Office Word. Padahal sudah tersedia perangkat lunak sejenis yang bersifat freeware, yaitu OpenOffice Writer; untuk pengolah data kuantitatif (spreadsheet), biasanya menggunakan MS Office Excel, padahal sudah tersedia OpenOffice Calc; untuk pengolah data presentasi biasanya menggunakan MS Office PowerPoint, padahal sudah tersedia OpenOffice Impress.

2. Banyak pihak yang masih menggunakan perangkat lunak pembaca file berekstensi PDF dengan Adobe Reader bajakan, padahal sudah tersedia freeware Nitro PDF Reader.
3. Untuk menonton file video di komputer, masih banyak orang menggunakan perangkat lunak bajakan seperti Cyberlink PowerDVD, Nero Vision Essentials, ketika sudah tersedia perangkat lunak yang tidak berbayar seperti $K$ Lite Media Player, KMPlayer.

4. Masih banyak pihak yang dengan bangga memutar file musik dengan perangkat lunak bajakan Winamp, tatkala sudah tersedia perangkat lunak gratis seperti DJ Player.

5. Untuk mempercepat akselerasi proses mengunduh, masih banyak orang yang menggunakan perangkat lunak bajakan Internet Download Manager (IDM), tatkala sudah tersedia perangkat lunak tidak berbayar seperti Orbit.

6. Kebanyakan orang masih menggunakan perangkat lunak bajakan Adobe Photoshop untuk memanipulasi photo, tatkala sudah tersedia perangkat lunak tidak berbayar seperti GIMP.

7. Untuk membakar file ke dalam media compactdisc, masih banyak orang yang menggunakan perangkat lunak bajakan Nero, tatkala sudah tersedia perangkat lunak gratis seperti jCDWriter.

Berdasarkan deskripsi tersebut, maka peneliti tertarik untuk mengadakan penelitian mengenai perspektif etika bisnis mahasiswa terhadap penggunaan software asli dan bajakan di Kotamadya Pontianak. adalah:

Adapun rumusan masalah dalam penelitian ini

1. Bagaimanakah perspektif etika bisnis mahasiswa terhadap penggunaan software asli dan bajakan di Kotamadya Pontianak?

2. Bagaimanakah tingkat pengetahuan mahasiswa terhadap sejumlah software yang bersifat tidak berbayar (freeware)?

\section{TINJAUAN TEORETIS}

\section{Tantangan-tantangan Manajemen di Era Ekonomi Digital}

Laudon dan Laudon (2005) menyatakan bahwa teknologi bisa menjadi pedang bermata dua. Teknologi bias menjadi sumber keuntungan. Satu keuntungan besar dari sistem komputer kontemporer adalah kemudahan menganalisis, kemudahan mengirimkan, dan berbagi-pakai informasi digital di antara banyak orang. Namun pada saat yang sama, kemampuan yang tangguh ini juga menciptakan peluang-peluang baru untuk berlawanan dengan hukum yang berlaku atau merugikan orang lain. Keseimbangan antara kenyamanan dan implikasi kebebasan pribadi dalam penggunaan teknologi $m$ - 
commerce untuk melacak pelanggan dan mengirimkan email iklan yang tidak diinginkan, merupakansalah satu isu etika yang menonjol yang ditimbulkan oleh sistem informasi kontemporer.

McLeod (2001) mengungkapkan bahwa dalam dunia bisnis, salah satu alasan utama terhadap perhatian etika adalah pembajakan perangkat lunak yang menggerogoti pendapatan penjual perangkat lunak hingga miliaran dollar setahun. Namun, subyek etika computer lebih dalam daripada masalah privasi dann pembajakan. Komputer adalah peralatan sosial yang penuh daya, yang dapat membantu atau mengganggu masyarakat dalam banyak cara. Semua tergantung pada cara penggunaannya.

Turban, et al (2006) menyatakan bahwa for years, movie studios suffered minor losses due to high-tech piracy (theft of digital content) that was carried out by people duplicating videotapes and DVD's.The need to produce and distribute physical media presented a number of technicel and logistical difficulties for movie pirates, which limited the scope of their operations. Thus, picture studios largely ignored these activities. When Napster.com and other sites began to use the web and peer-to-peer technologies to share pirated music, movie producers felt reasonably immune to this trend. After all, it would take more than a week to download a 5 gigabyte DVD-quality movie using a 56-kbps modem. However, as information technology continued to envolved, video compression algorithms made it possible to shrink the size of the movies to 650 megabytes, while the explotion of high-speed internet connections made it much easier to download and share large files. Today, a user with a broadband connection can download a movie in 2 to 8 hours. The MPAA reports that in 2003 more than 50 major films were illegally copied and released even before they came out in movie theaters.

\section{Pengertian Moral}

McLeod (2001) mengungkapkan bahwa moral adalah tradisi kepercayaan perilaku benar dan salah. Moral adalah institusi sosial dengan suatu sejarah dan daftar peraturan. Manusia mulai mempelajari peraturan-peraturan dari perilaku moral sejak anakanak. Saat manusia tumbuh dan matang secara fisik dan mental, manusia mempelajari peraturanperaturan yang masyarakat harapkan untuk diikuti. Peraturan-peraturan tingkah laku ini adalah moral manusia. Walau berbagai masyarakat tidak mengikuti satu set moral yang sama, terdapat keseragaman kuat yang mendasar. Melakukan apa yang benar secara moral merupakan landasan perilaku sosial manusia.

\section{Dimensi Moral Era Informasi}

Laudon dan Laudon (2005) menyatakan bahwa isu-isu etika, sosial, dan politik yang penting diangkat oleh sistem informasi mencakup dimensidimensi moral sebagai berikut:

a. Hak-hak informasi dan kewajiban: hak-hak informasi apa yang dimiliki oleh individu dan organisasi yang berkaitan dengan informasi mengenai dirinya sendiri? Apa saja yang bisa dilindunginya? Kewajiban-kewajiban apa yang dimiliki oleh individu dan organisasi mengenai informasi tersebut?

b. Hak kepemilikan: Bagaimana hak milik intelektual tradisional bisa terlindungi dalam masyarakat digital di mana pelacakan dan pelaporan mengenai kepemilikan sangat susah dilakukan, dan mengabaikan hak milik seperti itu sangat mudah untuk dilakukan?

c. Pertanggungjawaban dan kontrol: Siapa yang bertanggungjawab atas segala kejadian yang merugikan informasi individu dan kolektif serta hak-hak kepemilikan?

d. Kualitas sistem: Standar baku apa untuk data dan kualitas sistem yang harus diminta untuk memberi perlindungan atas hak-hak individu dan keamanan masyarakat?

e. Kualitas hidup: Nilai-nilai apa yang harus dipelihara dalam masyarakat informasi dan pengetahuan? Institusi apa yang harus kami lindungi dari penyalahgunaan terhadap informasi? Nilai-nilai kultural dan praktikpraktik apa yang didukung oleh teknologi informasi baru?

\section{Pengertian Etika Komputer}

Menurut McLeod (2001) etika adalah satu set kepercayaan, standar, atau pemikiran yang mengisi suatu individu, kelompok, atau masyarakat. Semua individu bertanggung jawab kepada masyarakat atas perilaku mereka. Masyarakat dapat berupa suatu kota, negara, atau profesi. Etika dapat sangat berbeda dari satu masyarakat ke masyarakat lain.

Moor dalam McLeod (2001) menyatakan bahwa etika komputer sebagai analisis mengenai sifar dan dampak sosial teknologi komputer, serta formulasi dan justifikasi kebijakan untuk menggunakan teknologi tersebut secara etis.

McLeod (2001) menerangkan bahwa etika komputer terdiri dari dua aktivitas utama, dan manajer yang paling bertanggung jawab atas aktivitas tersebut adalah $C I O$. $C I O$ harus: 
a. Waspada dan sadar bagaimana komputer mempengaruhi masyarakat,

b. Berbuat sesuatu dengan memformulasikan kebijakan-kebijakan yang memastikan bahwa teknologi tersebut digunakan secara tepat.

Namun, ada satu hal yang sangat penting; bukan hanya CIO sendiri yang bertanggung jawab atas etika komputer. Keterlibatan seluruh perusahaan merupakan keharusan mutlak dalam dunia end-user computing saat ini, semua manajer di semua bidang bertanggung jawab atas penggunaan komputer yang etis di bidang mereka. Dan setiap pegawai bertanggung jawab atas aktivitas mereka yang berhubungan dengan komputer.

\section{Perlunya Etika Komputer}

Moor dalam McLeod (2001) menyatakan ada tiga alasan utama atas minat masyarakat yang tinggi pada etika komputer, yaitu:

a. Kelenturan logis (logical malleability); adalah kemampuan memprogram komputer untuk melakukan apa pun yang kita inginkan. Komputer bekerja tepat seperti yang diinstruksikan oleh programernya. Kelenturan logis inilah yang menakutkan masyarakat. Tetapi masyarakat sebenarnya tidak terhadap komputer. Sebaliknya masyarakat takut terhadap orangorang yang memberi perintah di belakang komputer.

b. Faktor transformasi; alasan kepedulian pada etika komputer ini didasarkan pada fakta bahwa komputer dapat mengubah secara drastis cara kita melakukan sesuatu. Contoh yang baik adalah email. Email tidak hanya memberikan cara bertelepon yang lain, tetapi memberikan cara berkomunikasi yang sama sekali baru.

c. Faktor tak kasat mata; komputer dipandang sebagai suatu kotak hitam. Semua operasi internal komputer tersembunyi dari penglihatan. Operasi internal yang tidak tampak ini membuka peluang pada nilai-nilai pemrograman yang tidak terlihat, perhitungan rumit dan penyalahgunaan yang tidak terlihat.

\section{Tren-tren Teknologi yang Mengangkat Isu-isu Etika}

Laudon dan Laudon (2005) menyatakan bahwa ada empat tren teknologi penting yang bertanggung jawab atas tekanan-tekanan etika dan keempatnya terangkum pada:

Tren:

1. Kekuatan komputasi berlipat ganda tiap 18 bulan.

2. Biaya atau ongkos penyimpanan data menurun secara drastis.

3. Kemajuan-kemajuan analisis data.
4. Kemajuan-kemajuan pada internet dan teknologi jaringan.

Dampak:

1. Semakin banyak organisasi bergantung pada sistem komputer untuk menjalankan operasioperasi yang penting.

2. Organisasi bisa dengan mudah membangun dan memelihara database individu secara lebih rinci.

3. Perusahaan bisa menganalisis sejumlah besar data secara cepat dan membuat profil individu terinci.

4. Semakin mudah menyalin dan mengakses data personil dari satu lokasi ke lokasi lainnya.

\section{Etika pada Masyarakat Informasi}

Laudon dan Laudon (2005) mengungkapkan bahwa etika berkaitan dengan manusia yang memiliki kebebasan memilih. Etika berkaitan dengan pilihan individu: sewaktu berhadapan dengan beragam alternatif tindakan, apa yang menjadi pilihan moral yang benar? Apa saja fiturfitur utama dari pilihan etis? Pilihan etis adalah keputusan yang diambil oleh individu yang bertanggung jawab atas konsekuensi dari tindakantindakannya, yang terdiri atas:

a. Tanggung jawab, berarti kita menerima segala bentuk biaya, tugas, dan keharusan dari keputusan yang dibuat.

b. Akuntabilitas, artinya mekanisme ada pada tempatnya dalam menentukan siapa yang bertanggung jawab, siapa yang bertindak.

c. Pertanggungjawaban secara hukum, artinya fitur sistem politik di mana badan hukum berada pada tempatnya yang mengizinkan individu untuk dipulihkan dari kerusakan atau kerugian yang diperbuat oleh pelaku lain, sistem, atau organisasi.

d. Proses hak, adalah fitur terkait dari masyarakat yang diatur secara hukum dan merupakan proses yang diketahui dan dipahaminya hukum serta ada kesanggupan mengarah ke otoritas yang lebih tinggi untuk memastikan bahwa hukum tersebut diterapkan secara benar.

\section{Prinsip-prinsip Etika}

Laudon dan Laudon (2005) merangkum beberapa prinsip yang telah berakar dalam banyak kultur yang bisa bertahan sepanjang sejarah, yaitu:

a. Berlakukah kepada orang lain sama seperti yang Anda inginkan agar orang lain berlaku kepada Anda (Golden Rule).

b. Jika suatu tindakan dianggap tidak baik dilakukan oleh setiap orang, maka tindakan itu 
tidak baik untuk semua orang (Kategori imperatif dari Emanuel Kant).

c. Jika suatu tindakan tidak bisa dilakukan secara berulang-ulang, maka tindakan itu tidak benar sama sekali (aturan perubahan dari Descartes).

d. Ambilah tindakan yang memiliki nilai lebih tinggi atau lebih besar (prinsip utilitarian).

e. Ambilah tindakan yang paling sedikit memberi kerugian, atau potensi kerugian yang terkecil (prinsip penolakan risiko).

f. Jika sesuatu yang dihasilkan oleh seseorang berguna bagi Anda, maka sesuatu itu memiliki nilai, dan Anda harus menganggap bahwa si pencipta menginginkan kompensasi atas tindakannya itu.

\section{Panduan Etis dalam Praktik Bisnis}

Parker, et al (1990) dalam McLeod (2001) menyatakan tujuh pertanyaan yang menentukan etika suatu tindakan, yaitu:

a. Apakah itu terhormat? Apakah Anda ingin menyembunyikan tindakan itu dari seseorang?

b. Apakah itu jujur? Apakah itu melanggar suatu perjanjian, nyata atau tersirat, atau menghianati suatu kepercayaan?

c. Apakah itu menghindari kemungkinan pertentangan kemungkinan? Adakah pertimbangan-pertimbangan lain yang mungkin membuat bias penilaian Anda?

d. Apakah itu berada dalam wilayah kemampuan Anda? Mungkinkah bahwa usaha terbaik Anda tidak memadai?

e. Apakah itu adil? Apakah itu merugikan kepentingan legitimasi pihak-pihak lain?

f. Apakah itu dipertimbangkan? Akankah itu melanggar kerahasiaan atau privasi, atau mungkin merugikan seseorang atau sesuatu?

g. Apakah itu konservatif? Apakah itu membuang waktu atau sumber daya lain yang berharga secara sia-sia?

Kekayaan Intelektual, Pembajakan, dan Penggunaan Secara Adil

Strickland (2003) menyatakan bahwa computer software, books, news articles, music, movies, paintings, and myriad other forms of intellectual property are becoming the dominant product of modern economic systems. Furthermore, information technology is intriducing entirely new ways in which intellectual property can be used, transmitted, and manipulated. Ironically, the same technology greatly enhances the possibilities to abuse the information and infringe on the rights of the authors and owners of the intelellectual property.
Hinduja (2003) mengungkapkan bahwa $a$ different approach to controlling piracy is to delegate the responsibility for preventing unauthorized copying to the creators of the intellectual property. Various copy protection mechanisms and digital rights management (DRM) systems demonstrate a feasible approach to limitating piracy. Unfortunately, this method is not perfect, pirates may devise tecniques to disable or bypass the copy protection systems.

Russell (2003) mengungkapkan bahwa restictive digital rights managements systems may be unable to differentiate between unlawful piracy and legal fair use. Thus, the systems may deny educators and reseachers the opportunity to use copyrighted materials, thereby limiting their ability to advance academic, scientific, and cultural progress that follows from teching and scholarship.

\section{Penelitian-penelitian sebelumnya}

Jamil, et al (2011) menyatakan bahwa Software companies, for example, Microsoft, Apple, Adobe, $I B M$, and so on, have directly suffered the effects from people using illegal software. "As broadband growth continues and the IT sector expands, the influx of new users and the increased availability of pirated software means continual efforts are required to reduce and Danish Jamil et al. keep software piracy down." The following section will discuss the actions against the violation of copyright software and the outcome of the pirate software in company view.

Theng, et al (2010) menyatakan bahwa copyright is a legal term used to describe rights given to creators for their literary and artistic works. This gives the original creators of works the exclusive rights to use or authorize others to use the work as agreed, and one of such rights is the reproduction rights. Computer program is a form of literacy works and has been included under the umbrella of works covered by copyrights as defined by WIPO. Software piracy is the attempt to make illegal copies from an original piece of software program and sell those illegal copies to consumers. Software counterfeiting is to package the pirated contents such that the result of the illegal software product "look and feel" as genuine as the original one. However, whether it is piracy or counterfeiting, the primary intent is similar and that is to copy someone else's work without formally seeking permission from the author.

McLennan dan Le (2011) menerangkan bahwa this paper demonstrates that the effects of IPRs violations on economic growth are significantly 
robust. Countries with increasing rates of property rights violations tend to have lower growth rates. In other words, when the means of production are disrupted, ignored, or even taken away, people become less productive, which in turn leads to lower economic growth. The results also show countries with strong governance to enact policies to protect property rights exhibit increasing growth. Thus, governments must introduce strong policies aiming at protecting IPRs to promote economic growth

\section{METODE PENELITIAN \\ Desain penelitian}

Penelitian ini merupakan riset eksploratori, menurut Maholtra (1996) dalam Simamora (2004) riset ini dapat dipakai untuk tujuan :

1. Merumuskan masalah agar lebih presisi.

2. Mengidentifikasi alternatif-alternatif keputusan atau tindakan.

3. Mengembangkan hipotesis.

4. Menentukan variabel dan hubungan-hubungan antarvariabel untuk diuji lebih lanjut.

5. Mencari ide untuk mengembangkan pendekatan terhadap masalah.

6. Mencari prioritas untuk riset selanjutnya.

Metode yang digunakan dalam penelitian ini adalah metode studi kasus. Metode studi kasus bertujuan untuk mencari informasi dari satu atau beberapa situasi yang sama dengan situasi masalah yang dihadapi peneliti..

\section{Teknik Pengumpulan Data}

Data dalam penelitian ini diperoleh melalui :

a. Observasi, yaitu pengumpulan data primer dengan cara mengamati secara sistematis untuk memperoleh informasi tentang fenomena yang diteliti.

b. Studi dokumenter yang dilakukan dengan cara mengkategorisasi (mengklasifikasi), kemudian mempelajari bahan-bahan tertulis yang berhubungan dengan masalah penelitian dan mengambil data atau informasi yang dibutuhkan. Sumbernya bisa berupa dokumen, buku, majalah, koran, dan lain-lain. Data yang diperoleh adalah data sekunder.

c. Komunikasi tidak langsung dengan menggunakan media komunikasi kuesioner.

\section{Teknik Analisis Data}

Untuk menjawab pertanyaan penelitian, alat analisis yang digunakan berdasarkan pada ukuran tendesi pusat yang terdiri dari:

a. Rata-rata (mean), yang dihitung dengan rumus

$$
=\frac{\sum_{i=1}^{n} X i}{n}
$$

b. Modus, yaitu nilai yang paling sering muncul.

\section{Skala Pengukuran Yang Digunakan}

Penelitian ini menggunakan skala linier numerik. Untuk pernyataan positif, maka skornya adalah sangat setuju $=4$, setuju $=3$, tidak setuju $=2$, dan sangat tidak setuju $=1$. Untuk pernyataan negatif, maka skor adalah sangat setuju $=1$, setuju $=2$, tidak setuju $=3$, dan sangat tidak setuju $=4$.

Untuk interpretasi data, digunakan perhitungan rentang skala, sebagai berikut:

$\mathrm{RS}=\frac{m-n}{b}$

$\mathrm{m}=$ skor tertinggi pada skala

$\mathrm{n}=$ skor terendah pada skala

$\mathrm{b}=$ jumlah kelas atau kategori yang dibuat.

Untuk pernyataan positif sebagai berikut:

STS $=1,00 \leq \mathrm{x} \leq 1,75$

TS $=1,75<\mathrm{x} \leq 2,50$

$\mathrm{S}=2,50<\mathrm{x} \leq 3,25$

$\mathrm{SS}=3,25<\mathrm{x} \leq 4,00$

Untuk pernyataan negatif sebagai berikut:

$\mathrm{SS}=1,00 \leq \mathrm{x} \leq 1,75$

$\mathrm{S}=1,75<\mathrm{x} \leq 2,50$

$\mathrm{TS}=2,50<\mathrm{x} \leq 3,25$

$\mathrm{STS}=3,25<\mathrm{x} \leq 4,00$

\section{Lokasi Penelitian}

Penelitian ini akan dilakukan di beberapa perguruan tinggi yang berlokasi di Kampus STIE Indonesia Pontianak dan STIE Pontianak.

\section{Sampel Penelitian}

Dalam penelitian ini sampel yang akan diambil sebanyak 100 mahasiswa. Sampel diambil dengan menggunakan teknik non-probability sampling dengan metode convenience sampling.

\section{HASIL DAN PEMBAHASAN}

Kuesioner yang dibagikan kepada para responden terdiri atas: 6 (enam) butir pernyataan mengenai Perspektif Etika Bisnis, 5 (lima) butir pernyataan mengenai Sikap Membajak Perangkat Lunak, dan 1 (satu) butir pertanyaan mengenai Pengetahuan Perangkat Lunak freeware.

Berikut hasil rerata per pernyataan:

Perspektif Etika Bisnis:

1. "Saya pikir pantas, apabila dalam melakukan transaksi TI hak individu tidak dilindungi", dengan skor rerata 3,50. Artinya responden memandang sangat setuju ada perlindungan hak individu ketika melakukan transaksi TI.

2. "Apabila saya memiliki kekayaan intelektual, menurut saya wajar saja apabila hak intelektual saya tidak dilindungi”, dengan skor rerata 3,58. 
Artinya responden memandang sangat setuju bahwa ada perlindungan terhadap hak intelektual.

3. "Saya merasa wajar, apabila ada pihak yang bertanggungjawab atas segala kejadian yang merugikan informasi individu dan kolektif serta hak-hak kepemilikan", dengan skor rerata 3,80. Artinya responden memandang sangat setuju bahwa ada pihak yang bertanggung jawab atas segala kerugian informasi individu dan kolektif serta hak-hak kepemilikan.

4. "Menurut saya pantas, apabila terdapat standar baku untuk data dan kualitas sistem yang harus diminta untuk memberi perlindungan atas hakhak individu dan keamanan masyarakat", dengan skor rerata 3,50. Artinya responden memandang sangat setuju bahwa ada standar baku untuk perlindungan atas hak-hak individu dan keamanan masyarakat.

5. "Saya pikir wajar, apabila terdapat nilai-nilai yang harus dipelihara dalam masyarakat informasi dan pengetahuan", dengan skor rerata 3,40 . Artinya responden memandang sangat setuju bahwa nilai-nilai harus dipelihara dalam masyarakat informasi dan pengetahuan.

6. "Apabila saya mendapat email/SMS yang bersifat spam dari pihak ketiga (perbankan, perusahaan finansial/perusahaan konten), saya merasa wajar", dengan skor rerata 3,80. Artinya responden memandang sangat tidak setuju bahwa ada email/SMS spam.

Sikap Membajak Perangkat Lunak:

1. "Saya mengetahui bahwa terdapat perangkat lunak bajakan", dengan skor rerata 3,70. Artinya responden menyatakan sangat mengetahui adanya perangkat lunak bajakan.

2. "Saya merasa wajar, apabila menggunakan perangkat lunak bajakan", dengan skor rerata 3,30. Artinya responden menyatakan sangat wajar apabila menggunakan perangkat lunak bajakan.

3. "Saya merasa tidak merugikan pihak lain ketika saya menggunakan perangkat lunak bajakan", dengan skor rerata 2,37. Artinya responden menyatakan setuju menggunakan perangkat lunak bajakan tidak merugikan pihak lain.

4. "Apabila terdapat perangkat lunak freeware, saya akan menggunakannya”, dengan skor rerata 2,60. Artinya responden menyatakan setuju akan menggunakan perangkat lunak freeware.

5. "Menurut saya pantas, apabila hak intelektual saya dihargai oleh pihak lain", dengan skor rerata 3,40 . Artinya responden menyatakan sangat setuju apabila hak intelektual dihargai oleh pihak lain.

Pengetahuan Mengenai Perangkat Lunak Freeware: Respon atas pertanyaan "Apakah Anda mengetahui perangkat lunak yang bersifat freeware?" sebagai berikut: dari 100 responden, 12\% menyatakan "Mengetahui", dan 78\% menyatakan "Tidak Mengetahui".

\section{SIMPULAN DAN SARAN \\ Simpulan}

1. Rerata untuk variabel Perspektif Etika Bisnis sebesar 3,60. Artinya rata-rata responden memiliki perspektif yang sangat baik terhadap etika bisnis.

2. Pembajakan perangkat lunak identik dengan tindakan pencurian.

3. Rata-rata responden menganggap sangat wajar apabila menggunakan perangkat lunak bajakan.

4. Rata-rata responden menyatakan bahwa menggunakan perangkat lunak bajakan tidak merugikan pihak lain.

5. Rata-rata responden menyatakan akan menggunakan perangkat lunak freeware.

6. Dari 100 responden, hanya $12 \%$ yang menyatakan mengetahui perangkat lunak freeware.

\section{Saran}

1. Peningkatan sosialisasi etika bisnis terutama yang berkaitan dengan penggunaan perangkat lunak, agar jumlah pembajakan perangkat lunak bisa diturunkan.

2. Peningkatan sosialisasi mengenai ketersediaan perangkat lunak freeware di lingkungan masyarakat.

3. Perlu penelitian lebih lanjut untuk mendapatkan hasil penelitian yang lebih berkualitas.

\section{DAFTAR PUSTAKA}

Hinduja, S., 2003, Trends and Patterns Among Online Software Pirates, Journal of Ethics and Information Technology.

Jamil, Danish, Hassan Zaki, 2011, Software Piracy Does Not Hurt Anyone?, International Journal of Engineering Science and Technology (IJEST), Vol. 3 No. 4 Edisi April.

Juniarto, Eko, 2010, Jejak Digital, Majalah Chip, Juli 2010, halaman 62.

Laudon, Kenneth C, Jane P. Laudon, 2005, Sistem Informasi Manajemen, Mengelola 
Perusahaan Digital, Edisi 8, Alih bahasa: Erwin Philippus, Yogyakarta, Penerbit Andi. McLennan, Patrick G, Quan V. Le, 2011, The Effects of Intellectual Property Rights Violations on Economic Growth, Scientific Research, Vol. 2.

McLeod, Raymond, 2001, Sistem Informasi Manajemen, Jilid 2, Edisi 7, Alih bahasa: Hendra Teguh, Jakarta, PT Prenhallindo.

Russell, C., 2003, Fair Use Under Fire”, Library Journal, Agustus, halaman 32.

Simamora, Bilson, 2004, Riset Pemasaran : Falsafah, Teori, dan Aplikasi, PT Gramedia Pustaka Utama, Jakarta.

Strickland, LS., 2003, Copyright's Digital Dilemma Today: Fair Use or Unfair Constraints?, Bulletin of the American Society for Information Science and Technology, OktNov, halaman 7.

Theng, Yin-Leng, We Tack Tan, May O. Lwin, Schuber Foo Shou-Boon, 2010, An Exploratory Study of Determinants and Corrective Measures for Software Piracy and Counterfeiting in the Digital Age, Computer and Information Science Journal, Vol. 3, No. 3, Edisi Agustus.

Turban, Efraim, Dorothy Leidner, Ephraim McLean, James Wetherbe, 2006, Information Technology for Management, Transforming Organizations In The Digital Economy, Edisi 5, US, John Wiley \& Sons (Asia) Pte Ltd. 